\title{
Autotuning of Gain-Scheduled pH Control: An Experimental Study
} Hsiao-Chung Chan, and Cheng-Ching Yu

Ind. Eng. Chem. Res., 1995, 34 (5), 1718-1729 • DOI: 10.1021/ie00044a023

Downloaded from http://pubs.acs.org on November 28, 2008

\section{More About This Article}

The permalink http://dx.doi.org/10.1021/ie00044a023 provides access to:

- Links to articles and content related to this article

- Copyright permission to reproduce figures and/or text from this article 


\title{
Autotuning of Gain-Scheduled pH Control: An Experimental Study
}

\author{
Hsiao-Chung Chan and Cheng-Ching Yu* \\ Department of Chemical Engineering, National Taiwan Institute of Technology, Taipei, Taiwan 10672, ROC
}

\begin{abstract}
$\mathrm{pH}$ control is known to be a difficult control problem. In this work, the gain-scheduled proportional-integral (PI) controller is used to overcome process nonlinearity. Using the gainscheduled PI controller the nonlinear control problem becomes the identification of the titration curve and the design of the PI controller. With necessary instrumentation and appropriate model parameterization, the titration curve can be found in a robust manner. Autotune identification is employed to estimate the titration curve first and goes on to find the nominal tuning constants. This is the gain-scheduled autotune identification (g-ATV) procedure. The g-ATV procedure is tested in a laboratory scale $\mathrm{pH}$ neutralization system. The results show that robust estimation of the titration curve can be achieved from continuous cycling. Furthermore, reliable and effective nonlinear $\mathrm{pH}$ control can be obtained in a realistic operating condition as shown in this experimental study.
\end{abstract}

\section{Introduction}

The control of $\mathrm{pH}$ is very important in many processes: wastewater treatments, chemical processes, and biochemical processes. On the process side, $\mathrm{pH}$ neutralization is a very fast and simple reaction. However, in terms of control, this has been recognized as a very difficult control problem (Shinskey, 1973; Gary, 1981; Gustafsson and Waller, 1983; Piovoso and Williams, 1985; Williams et al., 1990; Wright and Kravaris, 1991; Lin and $\mathrm{Yu}, 1993)$. The difficulties arise from strong process nonlinearity (the process gain can change tens or hundreds of times over a small $\mathrm{pH}$ ranges) and frequent load changes (the process nonlinearity changes as the influent component varies). Therefore, a workable $\mathrm{pH}$ control methodology should have the following features: (1) reliable estimation of process nonlinearity (titration curve) and (2) nonlinear compensation.

Several approaches have been proposed for nonlinear $\mathrm{pH}$ control. These include gain-scheduled PI control (Shinskey, 1973; Gary, 1981; Gulaian and Lane, 1990; Lin and $\mathrm{Yu}, 1993$ ), reaction invariant control of Gustafsson and Waller (1983), nonlinear generic model control of Williams et al. (1990), and strong acid equivalent PI control of Wright and Kravaris (1991). Despite apparent differences in these approaches, the process titration curve is estimated explicitly or implicitly for nonlinear compensation. The importance of the static titration curve can be understood from the analysis of the $\mathrm{pH}$ neutralization process since, generally, $\mathrm{pH}$ processes consist of a nonlinear steady-state gain and a fairly linear process dynamic (in terms of transfer function; Åström and Wittenmark, 1989).

For a robust estimation of the titration curve, several points should be emphasized. First, the instrumentation requires more than one $\mathrm{pH}$ sensor to avoid the lack of degree of freedom in the regression (Williams et al., 1990; Lin and $\mathrm{Yu}, 1993)$. Second, the process understanding can play a role in the titration curve estimation. Over months or years of operation, the operators should have a fairly good idea about the variation of titration curves. The idea of using a linear combination of two (or more) known titration curves (Gulaian and

* To whom all correspondence should be addressed. Email: ccyu@ch.ntit.edu.tw.
Table 1. Typical Operating Condition for the pH Neutralization Process

\begin{tabular}{clcl}
\hline parameters & \multicolumn{1}{c}{ values } & parameters & \multicolumn{1}{c}{ values } \\
\hline$V$ & $4.50 \mathrm{~L}$ & $\mathrm{HAc}$ & $0.015 \mathrm{~N}$ \\
$F_{\text {acid }}$ & $0.476 \mathrm{~L} / \mathrm{min}$ & $F_{\text {base }}$ & $0.022 \mathrm{~L} / \mathrm{min}$ \\
$\mathrm{HCl}$ & $0.02 \mathrm{~N}$ & $\mathrm{NaOH}$ & $0.75 \mathrm{~N}$
\end{tabular}

Lane, 1990; Lin and Yu, 1993) offers the opportunity for operator involvement.

Once the static titration curve is available, the next step is to find the controller parameters at the nominal operating condition. Autotune variation (ATV) identification has been shown to work satisfactorily for a nonlinear process (Åström and Hägglund, 1984; Luyben, 1987). Nonlinear ATV has also been proposed (Luyben and Eskinat, 1994; Lin and Yu, 1993).

In terms of experimental design for systems identification, one needs to estimate the titration curve and find nominal controller parameters for $\mathrm{pH}$ control. Furthermore, the method has to work under operating conditions (e.g., under the conditions of process noise, imperfect mixing, reasonable process excitation, etc.). The purpose of this work is to extend the nonlinear autotuning procedure of Lin and $\mathrm{Yu}$ (1993) to handle the severe operating environment and to test it experimentally. This paper is organized as follows. The pH neutralization process, parameterization and identification of the titration curve, nonlinear compensation, nominal tuning, and g-ATV procedure are given in section 2 . Section 3 describes the instrumentation, cross validation, and experimental results, followed by the conclusion.

\section{Gain-Scheduled Autotune Variation (g-ATV)}

2.1. Process Description. The process simulated and evaluated experimentally is a $\mathrm{pH}$ neutralization system with a continuously stirred tank reactor (CSTR) configuration. The process stream is a mixture of a strong acid ( $\mathrm{HCl}$ ) and a weak acid (HAc) with the flow rate $F_{\text {acid }}$ and $\alpha_{1}$ and $\alpha_{2}$ correspond to the concentration of $\mathrm{HCl}$ and $\mathrm{HAc}$, respectively. The titration stream is a strong base $(\mathrm{NaOH})$ with a much higher concentration $\beta_{1}$ and a much smaller flow rate $F_{\text {base. }}$. Table 1 gives the typical steady-state operating condition. Since the reactor vessel has an overflow design, the volume is kept constant at $V=4.5 \mathrm{~L}$. 
2.2. Modeling Titration Curve. Since, in $\mathrm{pH}$ control, the titration curve is used for nonlinear compensation, the control relevant modeling for process nonlinearity should be simple and yet effective. For the wastewater neutralization process, it is nearly impossible to identify all the species and their concentrations in the influent (e.g., considering the terms BOD (biological oxygen demand) and COD (chemical oxygen demand) used in describing the characteristics of wastewater), especially when frequent and severe load changes are often encountered. Therefore, it is impractical and unnecessary to rigorously model all the species and their concentrations for the purpose of nonlinear compensation in the feedback loop.

On the other hand, the operators generally have some idea about the physical shape of the titration curve. Or, a number of titration curves can be found by titrating the influent over a period of process operation. One can utilize this knowledge to construct a model for the titration curve. A simple approach, for the convenience of regression, is to formulate the current titration curve as a linear combination of two base titration curves. This results in a linear least square regression. These two base titration curves can be found either rigorously from all possible titration curves or heuristically by spotting the most dissimilar curves (Lin and Yu, 1993). A simple rule of thumb is to find one curve with some buffering capacity (weak acid characteristic) and another curve without buffering capacity (strong acid characteristic). The formulation for the base titration curve can be in a species-based form (physical model) or in an empirical form (e.g., in the form of a polynomial). Without loss of generality, in this work, the base titration curve is expressed analytically.

Consider the system described in Table 1 . The constraint of electroneutrality leads to

$$
\begin{aligned}
\frac{r}{r+1} \beta_{1}-\frac{1}{r+1}\left[\alpha_{1}+\frac{\alpha_{2}}{1+10^{\left(\mathrm{p} K_{\mathrm{a}, 2}-\mathrm{pH}\right)}}\right]+ \\
10^{-\mathrm{pH}}-10^{\mathrm{pH}-\mathrm{p} K_{\mathrm{w}}}=0
\end{aligned}
$$

where $r$ denotes the ratio of the flow rate $F_{\text {base }} /\left(F_{\text {acid }}+\right.$ $\left.F_{\text {base }}\right), K_{\mathrm{a}, 2}$ denotes the dissociation constant for HAc and $\mathrm{p} K_{\mathrm{a}, 2}=-\log _{10} \mathrm{~K}_{\mathrm{a}, 2}, K_{\mathrm{w}}$ is the dissociation constant for water, and $\mathrm{p} K_{\mathrm{w}}=-\log _{10} K_{\mathrm{w}} . \alpha_{1}$ and $\alpha_{2}$ are the influent concentrations of $\mathrm{HCl}$ and $\mathrm{HAc}$, respectively. $\beta_{1}$ is the concentration of titrant. This equation characterizes the titration curve:

$$
T(r, \mathrm{pH})=0
$$

Similarly, the $i$ th base titration curve can be expressed as

$$
\begin{array}{r}
T_{i}(r, \mathrm{pH})=\frac{r}{r+1} \beta_{1}-\frac{1}{r+1}\left[\alpha_{1, i}+\frac{\alpha_{2, i}}{1+10^{\left(\mathrm{p} K_{\mathrm{a}, 2}-\mathrm{pH}\right)}}\right]+ \\
10^{-\mathrm{pH}}-10^{\mathrm{pH}-\mathrm{p} K_{\mathrm{w}}}=0
\end{array}
$$

where $\alpha_{1, i}$ and $\alpha_{2, i}$ are the influent concentrations of $\mathrm{HCl}$ and HAc for the $i$ th titration curve, respectively. From the linear combination formulation, this can be expressed as

$$
T(r, \mathrm{pH})=\theta T_{1}(r, \mathrm{pH})+(1-\theta) T_{2}(r, \mathrm{pH})+\xi=0
$$

where $\theta$ and $\xi$ are two unknown parameters. Therefore, the nonlinear titration curve can be expressed as a linear combination of two nonlinear functions $\left(T_{1}\right.$ and

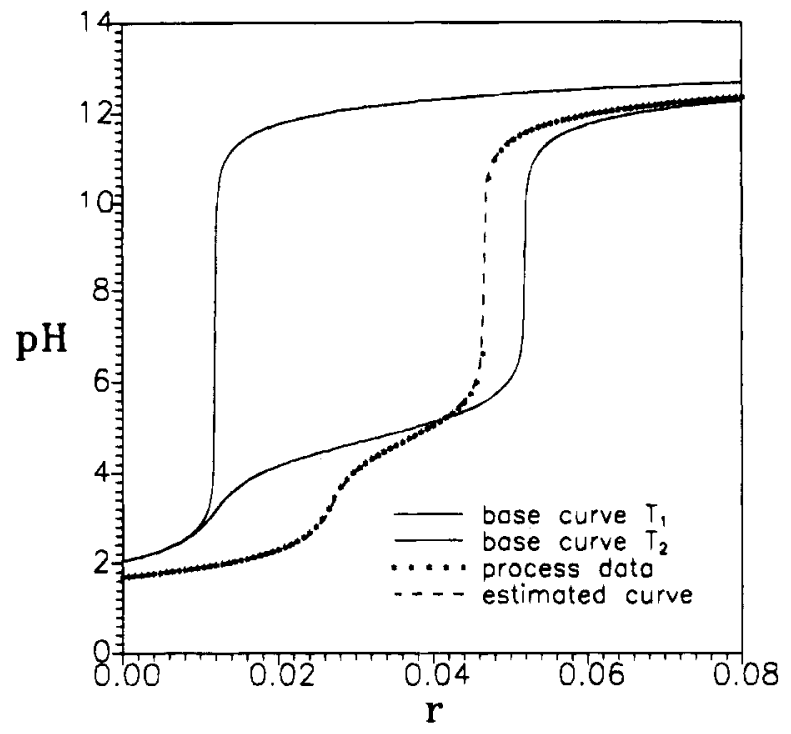

Figure 1. True and estimated titration curves for a mixture of $\mathrm{HCl}$ and HAc from two base titration curves $\left(T_{1}\right.$, top curve, and $T_{2}$ ).

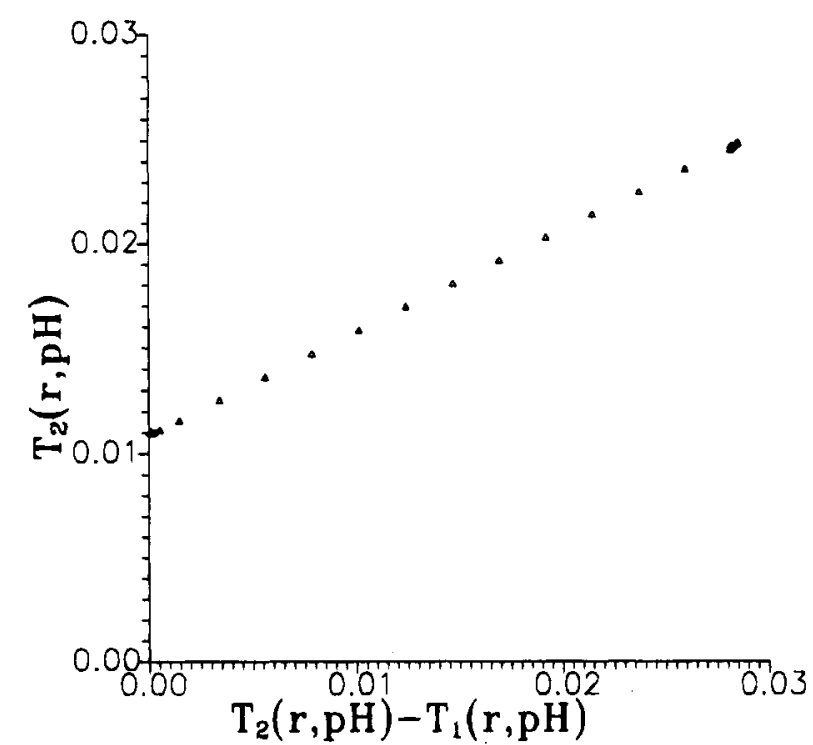

Figure 2. Alternative parameterization of the process titration curve.

$T_{2}$ ). Rearrangment of eq 4 into a convenient form for linear regression gives

$$
T_{2}(r, \mathrm{pH})=\theta\left[T_{2}(r, \mathrm{pH})-T_{1}(r, \mathrm{pH})\right]-\xi
$$

Therefore, a new titration curve (eq 4) can be constructed once process data, $r$ 's and $\mathrm{pH}$ 's, are available.

In this work, the two base titration curves $\left(T_{1}\right.$ and $T_{2}$ ) are selected by minimizing the AAD (absolute average deviation; Lin and Yu, 1993). Figure 1 shows the estimated titration curve $(T)$ and the corresponding base titration curves $\left(T_{1}\right.$ and $\left.T_{2}\right)$ for the system studied (Table 1). The Appendix gives the expression and coefficients for the base titration curve. The process data in Figure 1 are obtained by titrating the mixture of $0.02 \mathrm{~N} \mathrm{HCl}$ and $0.015 \mathrm{~N} \mathrm{HAc}$ with $0.75 \mathrm{~N} \mathrm{NaOH}$. In terms of the linear expression for the titration curve (eq $5)$, the process data show a straight line in the $T_{2}-\left(T_{2}\right.$ $-T_{1}$ ) plane (Figure 2).

2.3. Experimental Design for Titration Curve Identification. The experimental design for identifying the nonlinearity for unknown dynamic systems is a 
difficult and poorly understood problem. However, process understanding, appropriate instrumentation, and model parameterization can greatly simplify the effort. As mentioned earlier, the neutralization process can be described successfully with a static nonlinearity titration curve. Second, the parameterization of the titration (eq 5) leads to a linear least square problem, finding the slope and intersection of a straight line (Figure 2). It is not difficult to find a straight line from an experiment. However, the line in Figure 2 corresponds to a wide range of $\mathrm{pH}$ variations in the CSTR $(\mathrm{pH}=2-13)$. In terms of experimental design, we need to excite the $\mathrm{pH}$ a great deal (resulted in significant deviation of $\mathrm{pH}$ from the set point) if only one $\mathrm{pH}$ sensor is used. However, if the $\mathrm{pH}$ in the influent is measured (corresponding to the point of $r=0$ in Figure 2), the straight line can be determined without too much process excitation.

When necessary instrumentation and appropriate model parameterization, the titration curve can be found in a straightforward manner. In this work, the titration curve is obtained while performing autotune identification (Luyben, 1987; Lin and Yu, 1993). In autotune identification, an ideal relay is placed in the feedback loop and relay switches as $\mathrm{pH}$ crosses the set point. Figure $3 \mathrm{~b}$ shows the relay feedback test for a relay height $(h)$ of $\pm 10 \%$. Figure 3a shows that the alternative expression for the titration curve gives a rather straight line. Notice that the points in the lower left corner of Figure 3a correspond to the $\mathrm{pH}$ in the inlet stream and the points in the upper right corner correspond to the variations in the $\mathrm{pH}$ from the experiment. Here, the flow ratios $r$ 's are taken as the steady-state value ( $r^{\text {set }}$ instead of $r^{\text {set }}+\Delta r$ and $r^{\text {set }}-\Delta r$. It is clear that it is nearly impossible to construct a straight line from data obtained from the relay feedback test only. By measuring influent $\mathrm{pH}$, the straight line can be found with little process excitation. Furthermore, the titration curve can be robustly identified for different relay heights and different noise levels (Chan, 1994).

2.4. Nominal Tuning with Nonlinear Compensation. Autotune identification has proven reliable in the design of the linear controller for nonlinear chemical processes (Luyben, 1987). Futhermore, it is a closedloop test, and the experiment has little effect on the process operation. Despite the fact that the titration curve estimation is rather robust with respect to the relay height employed in the identification, the estimated ultimate gain $\left(K_{\mathrm{u}}\right)$ and ultimate frequency $\left(\omega_{\mathrm{u}}\right)$ are relatively sensitive to the changes in the relay height.

Since the neutralization process is rather nonlinear, asymmetric $\mathrm{pH}$ responses become more and more apparent as the relay height increases as shown in Figure 4 . In the case of asymmetric responses, the amplitude of the process output, $a$, is taken as the average of the oscillation:

$$
a=\frac{\mathrm{pH}^{\max }-\mathrm{pH}^{\min }}{2}
$$

where $\mathrm{pH}^{\max }$ and $\mathrm{pH}^{\min }$ denote the maximum and minimum values of the $\mathrm{pH}$ in the continuous cycling, respectively. Unfortunately, this nonlinear behavior gives a significantly different value in the ultimate gain $\left(K_{\mathrm{u}}\right)$. Table 2 shows that the deviation in $K_{\mathrm{u}}$ changes
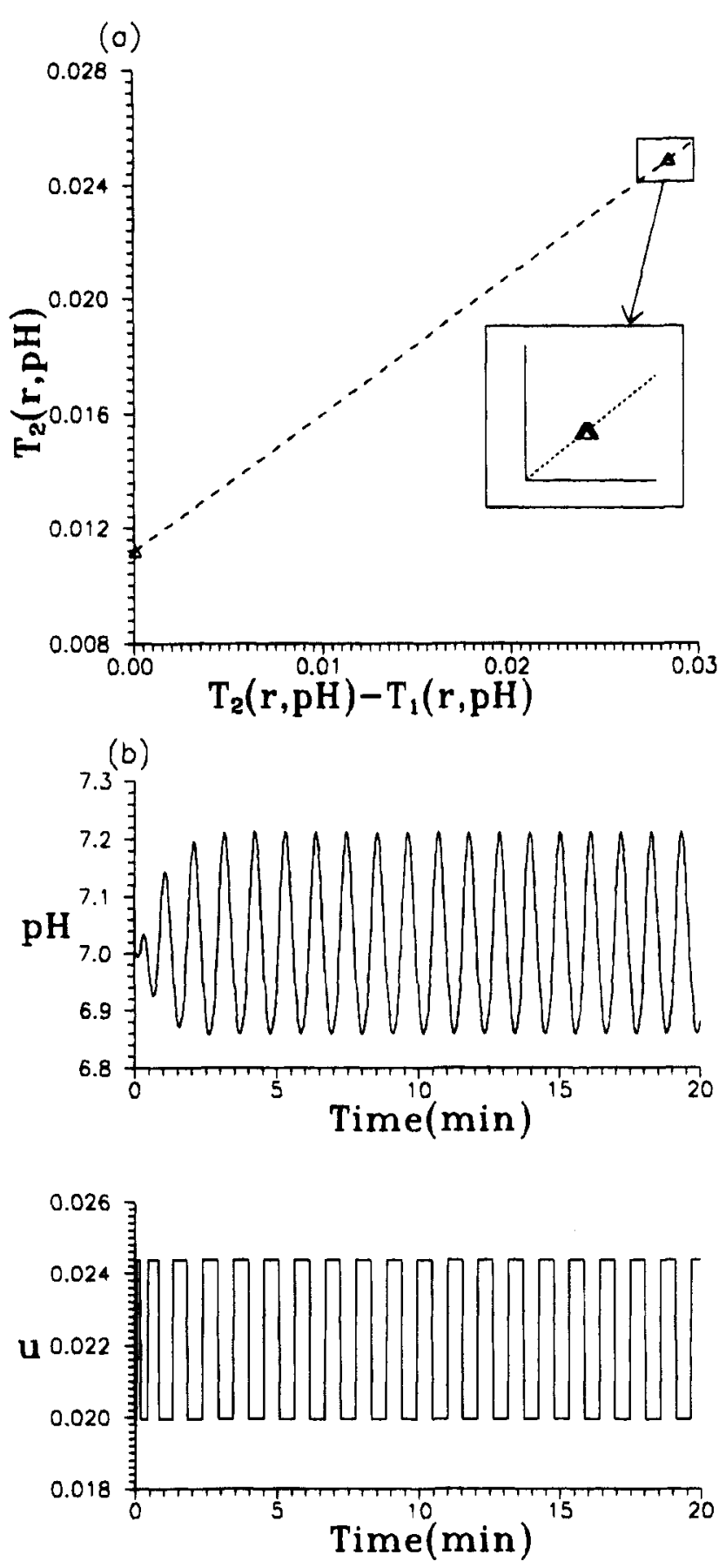

Figure 3. (a) Alternative expression for the titration curve from an ATV test and (b) process responses from an ATV test.

by a factor of $26 \%$ as the height of the relay increases to $20 \%$ of its nominal value.

Therefore, an alternative is to perform nonlinear compensation (from titration curve) first, followed by the tuning of nominal PID parameters. The nonlinear compensation comes strictly from the estimated titration curve. Figure 5 shows the block diagram for the gainscheduled PI control. The process gain is compensated via the block $K_{\mathrm{p}}(7) / K_{\mathrm{p}}^{*}(\mathrm{pH})$. From the titration curve, $K_{\mathrm{p}}^{*}(\mathrm{pH})$ corresponds to the slope of the line that intersects $\mathrm{pH}^{\text {set }}$ and the current $\mathrm{pH}$ value.

$$
K_{\mathrm{p}}^{*}(\mathrm{pH})=\frac{\mathrm{pH}^{\mathrm{set}}-\mathrm{pH}}{r^{\text {set }}-r}
$$

where $\mathrm{pH}^{\text {set }}$ and $\mathrm{pH}$ denote the values of the set point 

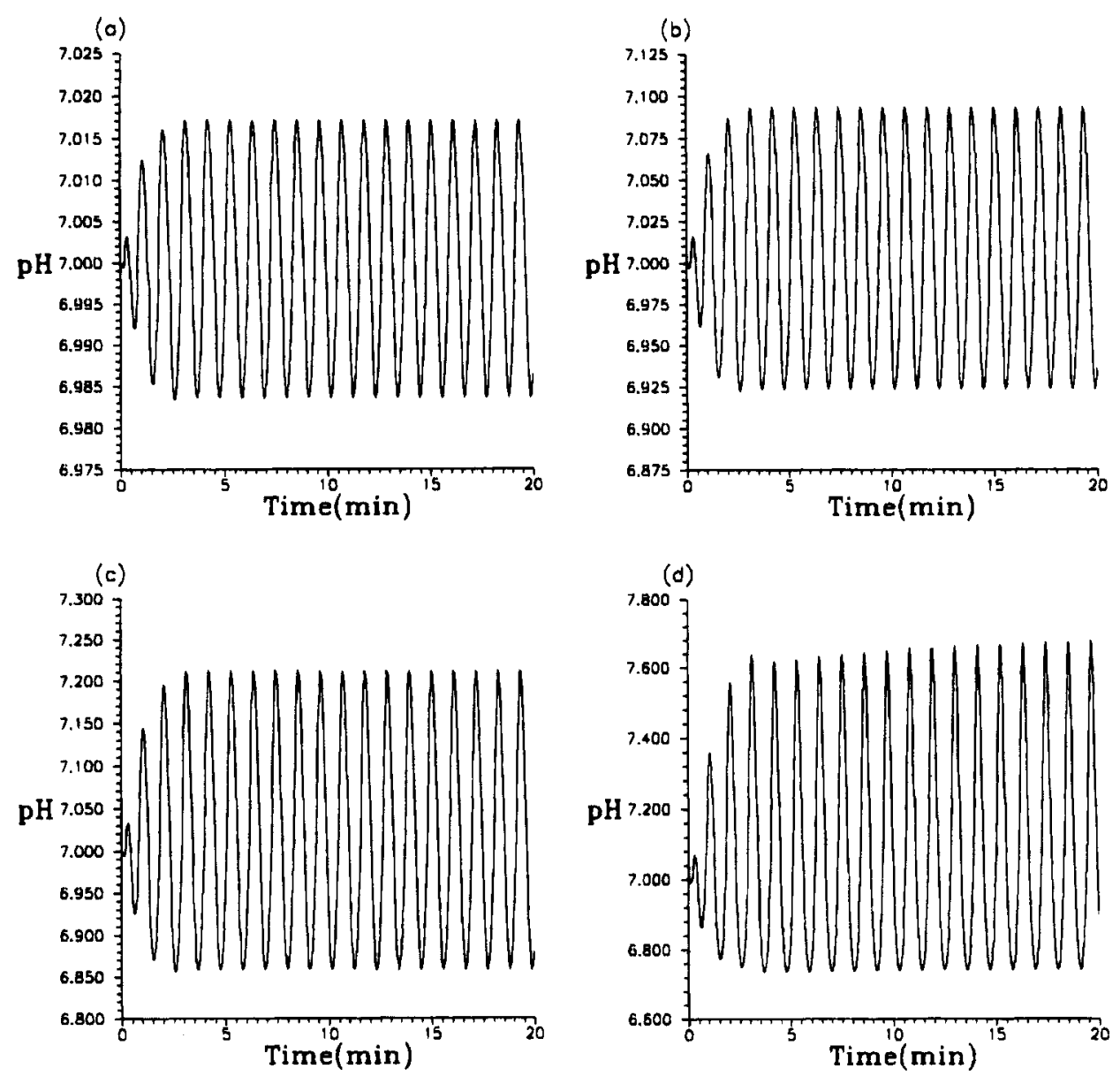

Figure 4. Effects of relay height (h) on system output in an ATV test: (a) $1 \%$, (b) $5 \%$, (c) $10 \%$, and (d) $20 \%$.

Table 2. Comparison of $K_{\mathrm{n}}$ and $\boldsymbol{P}_{\mathrm{u}}$ Using Different Relay Heights $(h)$ with $\left(e_{x}\right)$ and without (e $\left.e_{\mathrm{pH}}\right)$ Nonlinear Compensation

\begin{tabular}{ccccccc}
\hline & \multicolumn{3}{c}{$e_{\mathrm{pH}}$} & \multicolumn{2}{c}{$e_{x}$} \\
\cline { 2 - 7 } relay height (\%) & $K_{\mathrm{u}}$ & error $^{a}(\%)$ & $P_{\mathrm{u}}(\mathrm{min})$ & & $K_{\mathrm{u}}$ & error $^{a}(\%)$ \\
\hline 0.1 & 0.0168739 & & 1.0800 & 0.0168993 & $P_{\mathrm{u}}(\min )$ \\
0.2 & 0.0168739 & 0.00 & 1.0800 & 0.0168993 & 0.00 & 1.0800 \\
1.0 & 0.0168648 & 0.05 & 1.0800 & 0.0168993 & 0.00 & 1.0800 \\
5.0 & 0.0166575 & 1.28 & 1.0800 & 0.0168993 & 0.01 & 1.0800 \\
10.0 & 0.0159927 & 5.22 & 1.0800 & 0.0168950 & 0.03 & 1.0800 \\
20.0 & 0.0124333 & 26.32 & 1.0950 & 0.0162560 & 3.81 & 1.0950
\end{tabular}

a Taking $K_{\mathrm{u}}$ of $0.1 \%$ relay height as the base value.

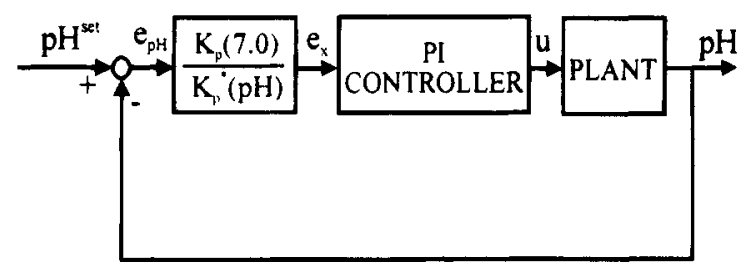

Figure 5. Block diagram for gain-scheduled PI control.

and current $\mathrm{pH}$ measurement, respectively, and $r^{\text {set }}$ and $r$ are the corresponding flow ratios read off from the titration curve. The transformed error $e_{x}$, then, becomes

$$
e_{x}=e_{\mathrm{pH}} \frac{K_{\mathrm{p}}(7)}{K_{\mathrm{p}}^{*}(\mathrm{pH})}
$$

where $e_{\mathrm{pH}}=\mathrm{pH}^{\text {set }}-\mathrm{pH}$. Following this nonlinear compensation, the autotune identification can be performed with respect to the transformed error $e_{x}$ (a relay inserted between $e_{x}$ and $u$ ). Figure 6 illustrates the g-ATV steps. First, an ATV test is performed with respect to $e_{\mathrm{pH}}$, and the titration curve can be estimated ( $\theta$ and $\xi$ can be found from Figure 3a). Once the nonlinear compensation block is established, the ATV test continues to find $K_{\mathrm{u}}$ and $\omega_{\mathrm{u}}$. Figure 6 clearly indicates that a rather symmetric cycling is observed (for $e_{x}$ at $t>11 \mathrm{~min}$ ), and the amplitude of the oscillation can be found in a straightforward manner. Moreover, the estimates of $K_{\mathrm{u}}$ and $\omega_{\mathrm{u}}$ are quite robust with respect to relay height $(h)$ as shown in Table 2 . In this work, a relaxed Ziegler-Nichols tuning rule is used (Shen and Yu, 1994):

$$
K_{\mathrm{c}}=\frac{K_{\mathrm{u}}}{3} \quad \tau_{\mathrm{I}}=\frac{P_{\mathrm{u}}}{0.5}
$$

2.5. Summary of Procedure. From the ongoing analyses, the automatic tuning and gain-scheduling procedure can be summarized as follows.

1. Collect all possible variations of the influent composition (e.g., in terms of titration curves or chemical composition). 

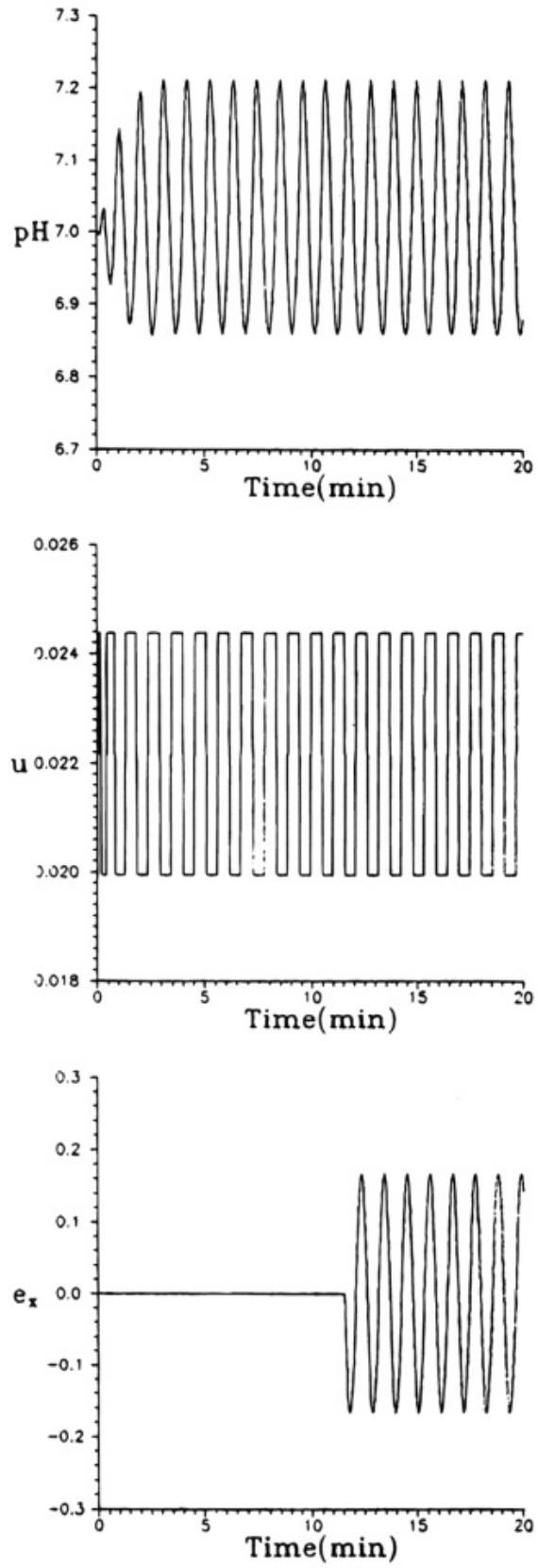

Figure 6. Process responses of a nonlinear-compensated ATV test with $h=10 \%$.

2. Select two base titration curves rigorously (calculating $\mathrm{AAD}$ for all possible pairs of titration curves) or heuristically (most dissimilar two).

3. Choose a relay height which gives appropriate process excitation.

4. Perform autotune identification. (a) Estimate the titration curve from the first few cyclings (eq 5 and Figure 3), and construct the nonlinear compensation block (eq 8 and Figure 5). (b) Estimate $K_{\mathrm{u}}$ and $\omega_{\mathrm{u}}$ from the nonlinear-compensated autotune identification (Figure 6).

5. Tune the PI constants from eq 9.

This completes the g-ATV procedure for nonlinear $\mathrm{pH}$ control.

\section{Experimental Section}

The proposed gain-scheduling ATV is tested on a $\mathrm{pH}$ neutralization process. In this section, the identification

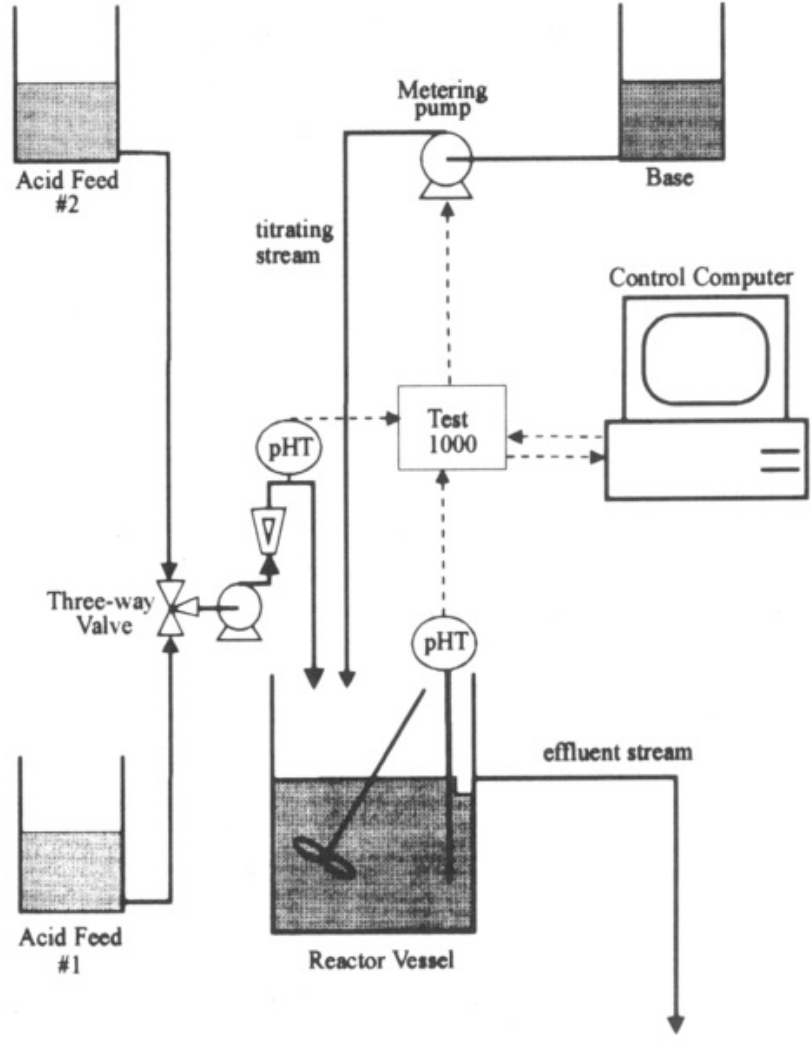

Figure 7. Diagram of experimental system.

and control steps are illustrated and the simulation and experimental results are compared.

3.1. Instrumentation and Control. The $\mathrm{pH}$ neutralization process uses $\mathrm{NaOH}$ to titrate a waste acid stream. The process stream consists of a strong acid $(\mathrm{HCl})$ and a weak acid (HAc), and the titrating stream is a more concentrated strong base $(\mathrm{NaOH})$. Table 1 gives the typical operating condition.

The process stream comes from two feed tanks (Figure 7), and a three-way valve is placed in the feedline which allows the switch between two different feed concentrations. The titratant comes from a $\mathrm{NaOH}$ tank and flows into the reactor vessel, and the flow rate is controlled using a metering pump (Figure 7). The reactor vessel has a volume of $4.5 \mathrm{~L}$, and the tank level is kept constant by designing an overflow system (Figure 7). An agitator is used to ensure proper mixing, and baffles are added to prevent the formation of a vortex. Figure 7 shows the experimental setup for the $\mathrm{pH}$ neutralization system.

The $\mathrm{pH}$ values in the influent and the CSTR are measured, and the process measurements are connected to a data acquisition system (Honeywell Test 1000) and then to an IBM compatible 80386 computer. A manual driven graphical interface is developed in BASIC under Test 1000 . The graphical system shows the process flow diagram and corresponding on-line process data. Process trends can also be displayed. The control objective is to maintain the $\mathrm{pH}$ value at the set point $\left(\mathrm{pH}^{\text {set }}=7\right)$. The control output is calculated according to the PI control law (or nonlinear-compensated PI control law), the digital output is converted to an analog output, and the signal is sent to a metering pump that adjusts the base flow rate. The sampling time for the measurements is $1 \mathrm{~s}$, and the control law is executed every $3 \mathrm{~s}$. The process measurements for the control are taken as the averaging values of three past $\mathrm{pH}$ values. Chan 

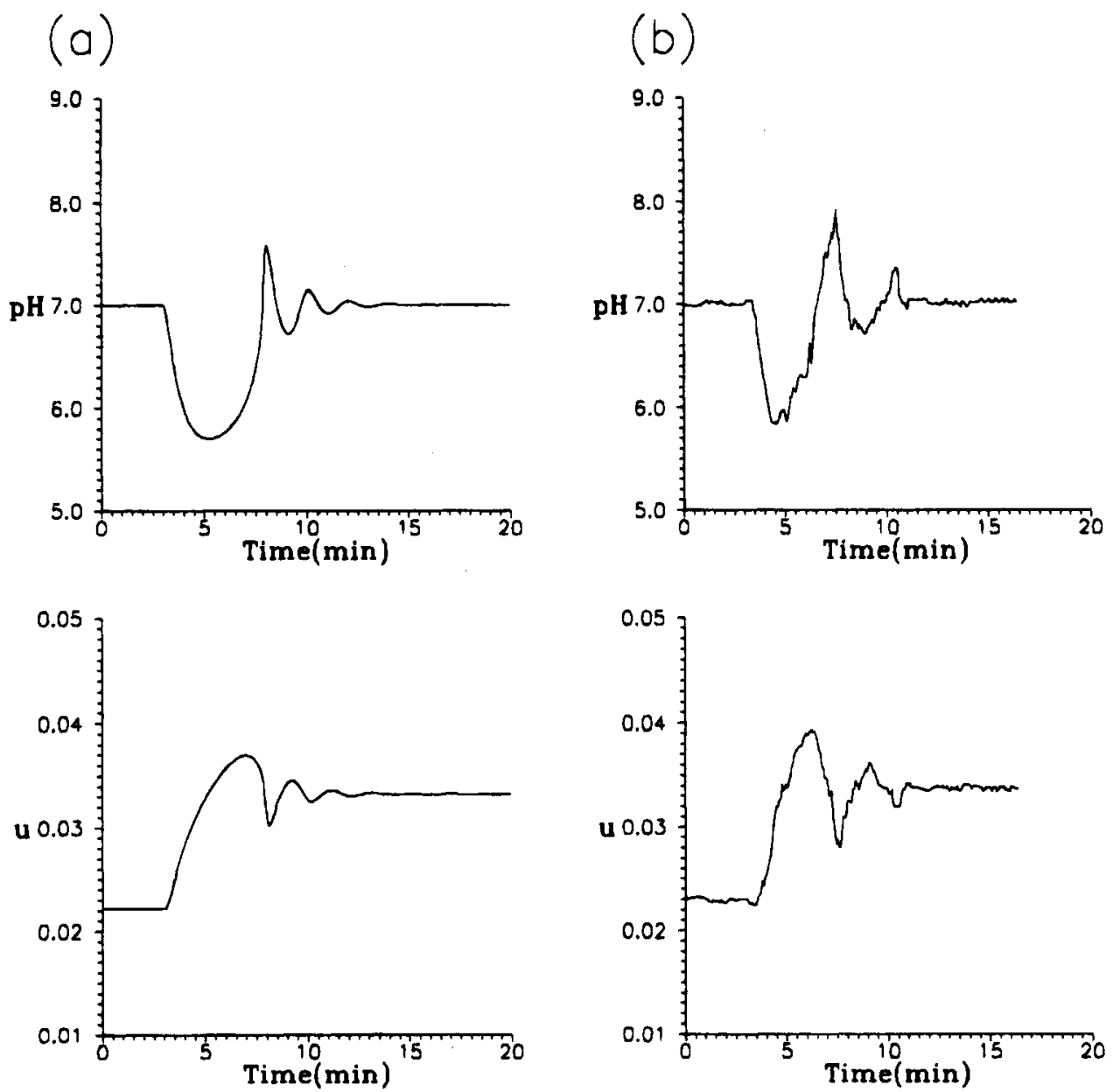

Figure 8. Load responses for a 50\% step increase in feed flow rate with fixed gain PI controller: (a) simulation and (b) experimental.

(1994) gives a detailed description and specifications on the instrumentation.

3.2. Cross (Model/Process) Validation. Before showing any result on g-ATV, comparison is made between the experimental results and the computer simulation. The model describing the $\mathrm{pH}$ neutralization process can be expressed as

$$
\begin{aligned}
& V \frac{\mathrm{d} y_{1}}{\mathrm{~d} t}=F_{\text {acid }} \alpha_{1}-F y_{1} \\
& V \frac{\mathrm{d} y_{2}}{\mathrm{~d} t}=F_{\text {acid }} \alpha_{2}-F y_{2} \\
& V \frac{\mathrm{d} x_{1}}{d t}=F_{\text {base }} \beta_{1}-F x_{1}
\end{aligned}
$$

The dependent variables $y_{1}, y_{2}$, and $x_{1}$ are the total ion concentrations of $\mathrm{HCl}, \mathrm{HAc}$, and $\mathrm{NaOH}$, respectively.

$$
\begin{gathered}
y_{1}=[\mathrm{HCl}]+\left[\mathrm{Cl}^{-}\right] \\
y_{2}=[\mathrm{HAc}]+\left[\mathrm{Ac}^{-}\right] \\
x_{1}=[\mathrm{NaOH}]+\left[\mathrm{Na}^{+}\right]
\end{gathered}
$$

$V$ is the volume of the reactor, $F_{\text {acid }}$ and $F_{\text {base }}$ correspond to the acid and base flow rates, respectively, and $F$ is the outlet flow rate. $\alpha_{1}$ and $\alpha_{2}$ are the feed concentrations of $\mathrm{HCl}$ and $\mathrm{HAc}$, respectively, and $\beta_{1}$ is the concentration of $\mathrm{NaOH}$. Furthermore, the value in the CSTR can be found by solving

$$
x_{1}-y_{1}-\frac{1}{1+10^{\left(\mathrm{p} K_{\mathrm{a}, 2}-\mathrm{pH}\right)}} y_{2}+10^{-\mathrm{pH}}-10^{\mathrm{pH}-\mathrm{p} K_{\mathrm{w}}}=0
$$

This model is solved numerically by integrating the ordinary differential equations using the Euler method, and the $\mathrm{pH}$ value is found by solving the nonlinear equation.

For the experiment as well as for the simulation, the PI controller parameters are obtained from the ATV tests followed by a Z-N type of tuning (eq 9). Figures 8 and 9 compare the simulation and experimental results for $+50 \%$ and $-50 \%$ step changes in the feed flow rate, respectively. The results show that closedloop responses from the computer simulation and lab scale experiments are quite similar to each other as shown in Figures 8 and 9. For a feed concentration change (a $50 \%$ step decrease in HAc concentration), Figure 10 shows the closed-loop responses for the simulation and experimental results. Again, qualitatively similar closed-loop responses are obtained. The comparison (Figures 8-10) clearly indicates the validity of the process model as well as the validity of the experimental setup.

3.3. Experimental Results. 3.3.1. Titration Curve Identification. The autotune identification (ATV) is carried out in the $\mathrm{pH}$ neutralization process. The $\mathrm{pH}$ response (Figure 11) is not quite as ideal as the simulation results (Figure 4). However, the titration 
1724 Ind. Eng. Chem. Res., Vol. 34, No. 5, 1995
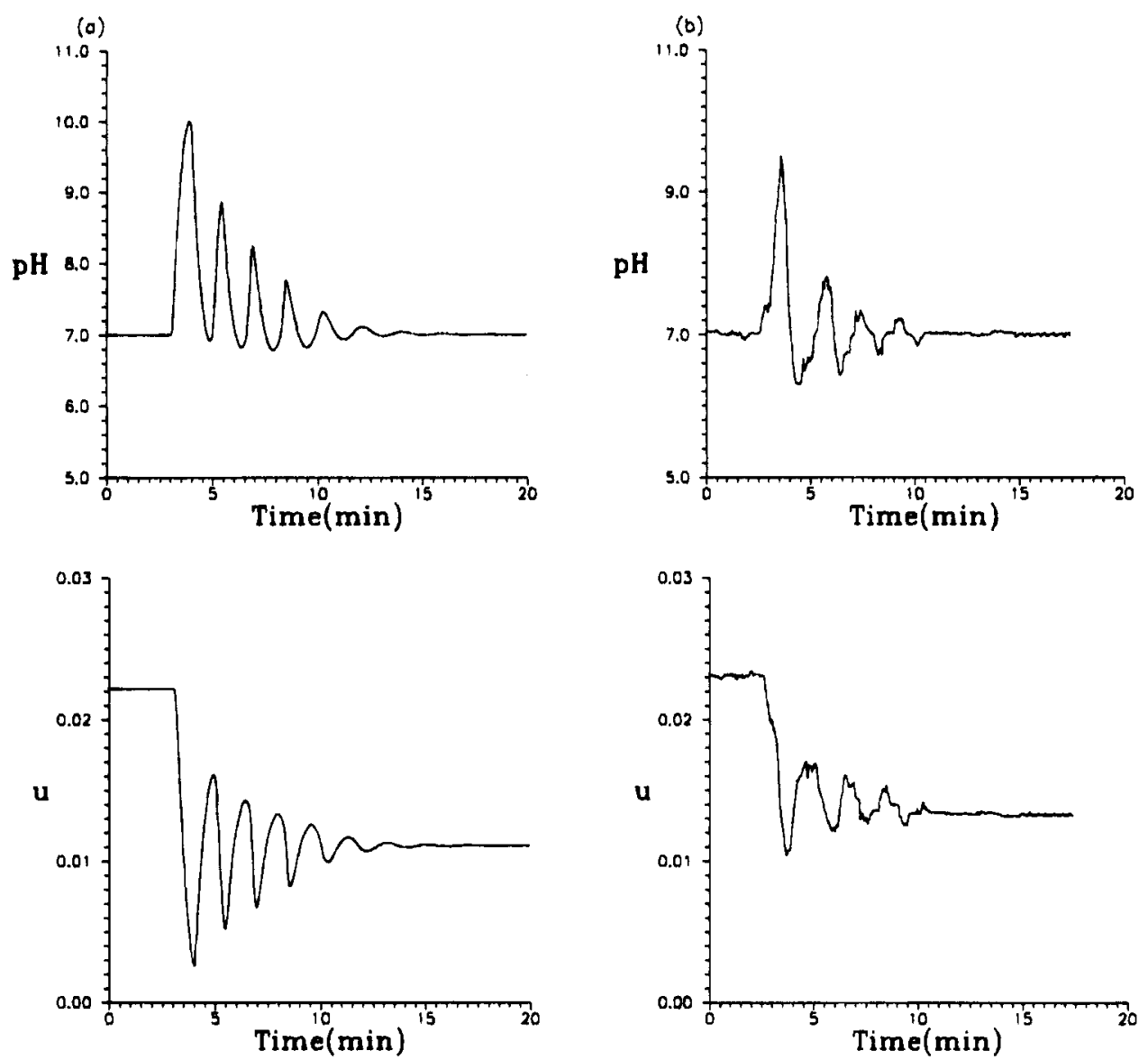

Figure 9. Load responses for a 50\% step decrease in feed flow rate with fixed gain PI controller: (a) simulation and (b) experimental.
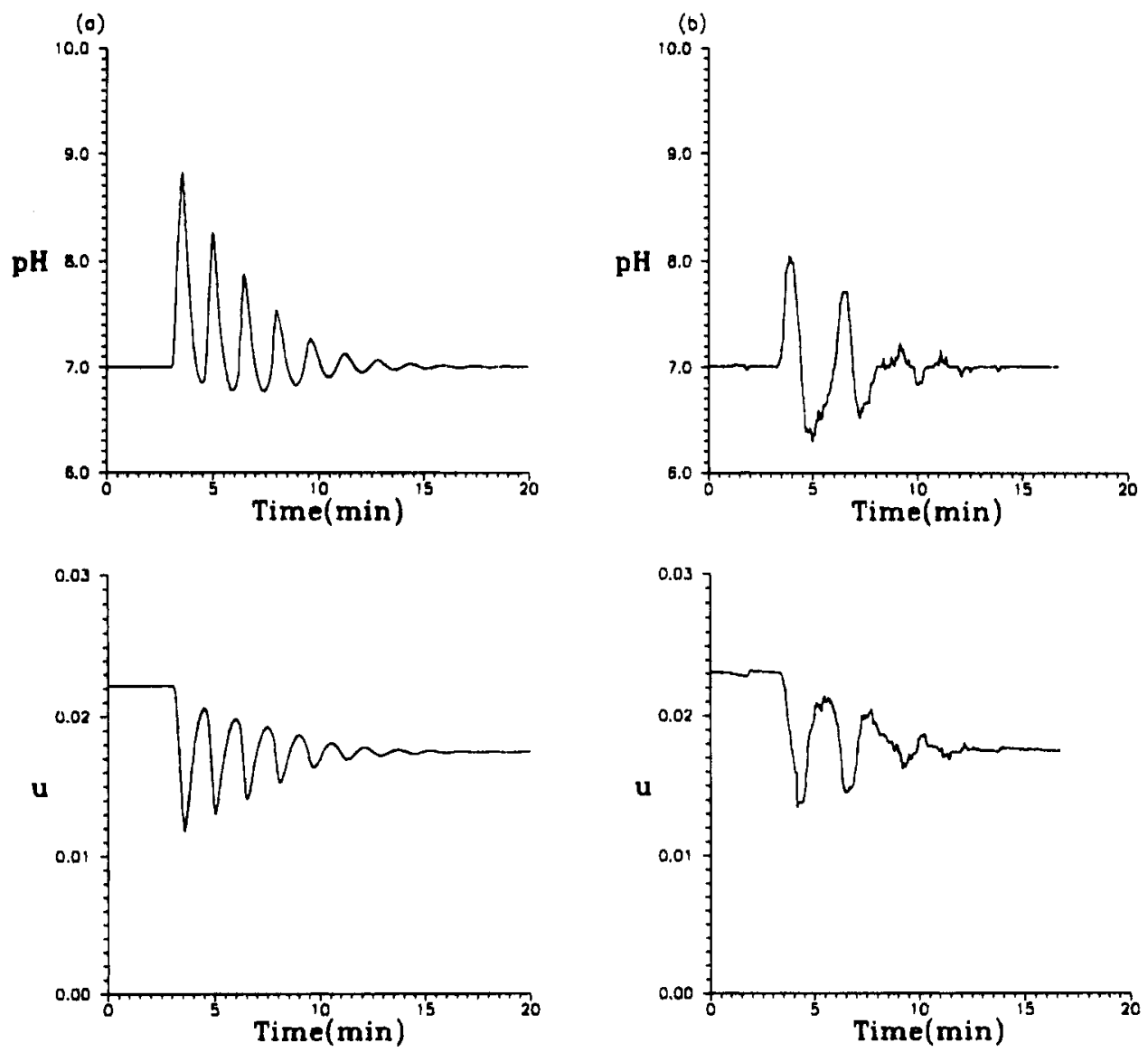

Figure 10. Load responses for a 50\% step decrease in weak acid (HAc) concentration with fixed gain PI controller: (a) simulation and (b) experimental. 

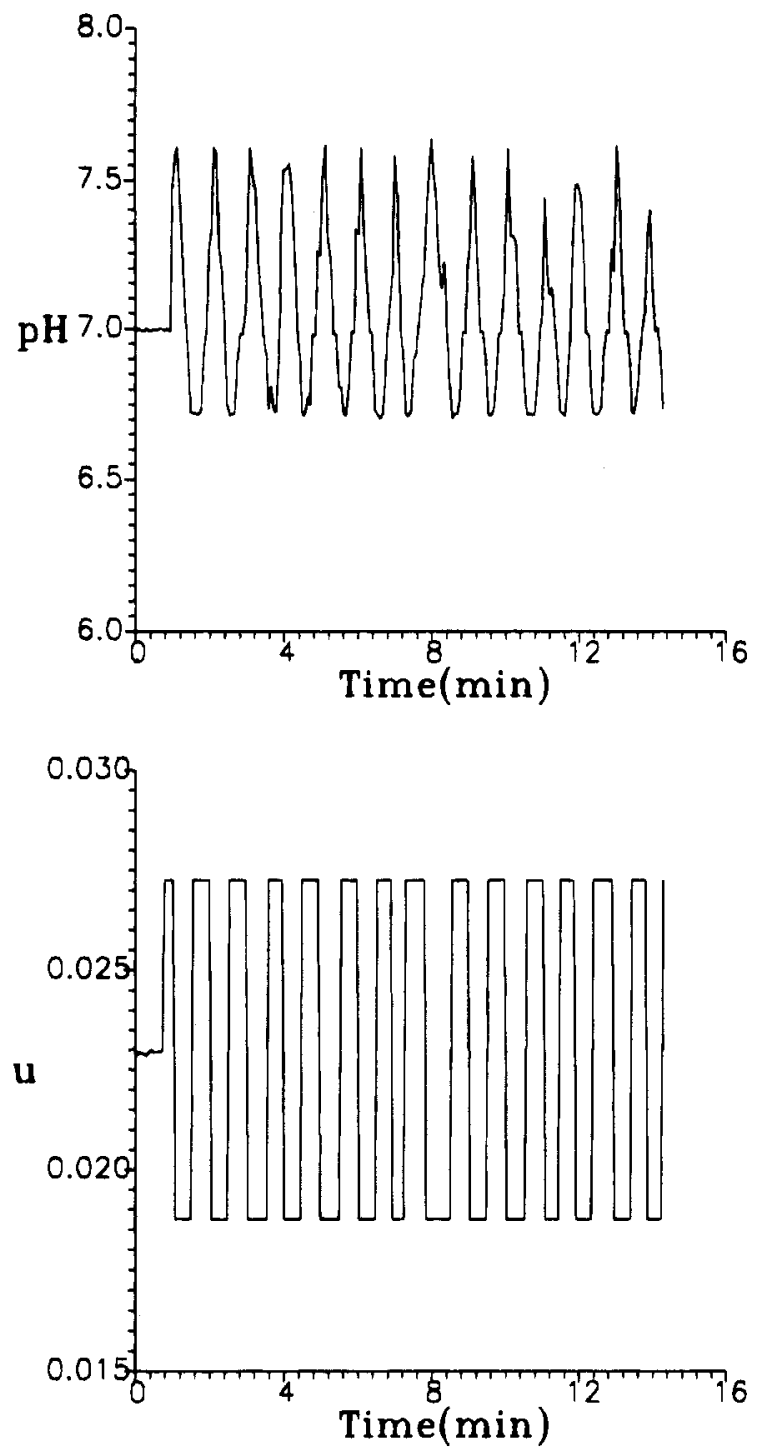

Figure 11. Experimental results from an ATV test on the $\mathrm{pH}$ neutralization process.

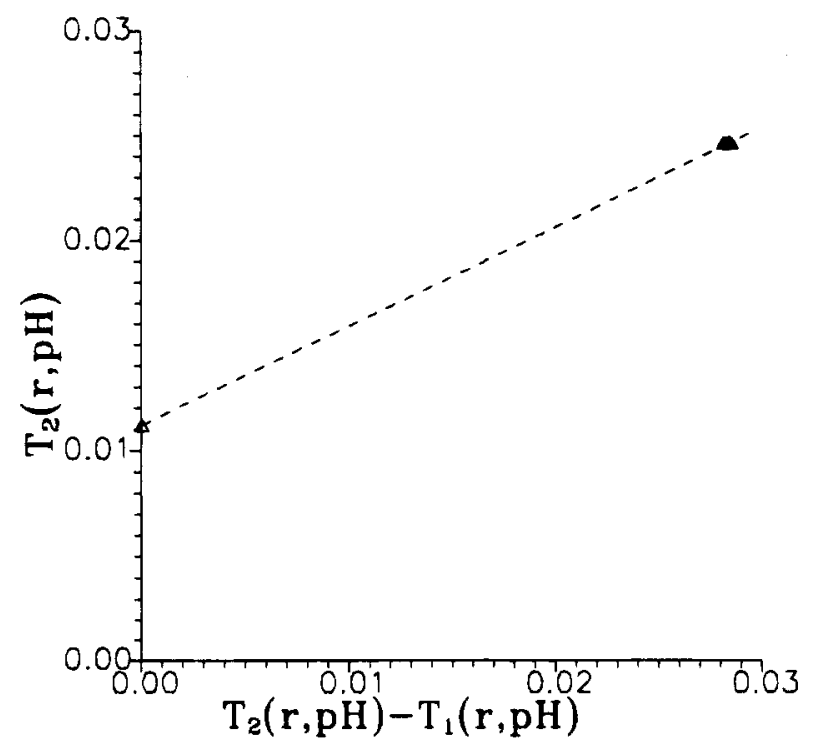

Figure 12. Alternative expression of the titration curve from the experimental results (Figure 11) of an ATV test.

curve can be effectively identified in terms of eq 5 as shown in Figure 12. Figure 12 comes from the first three $\mathrm{pH}$ oscillations of Figure 11. The experimentally
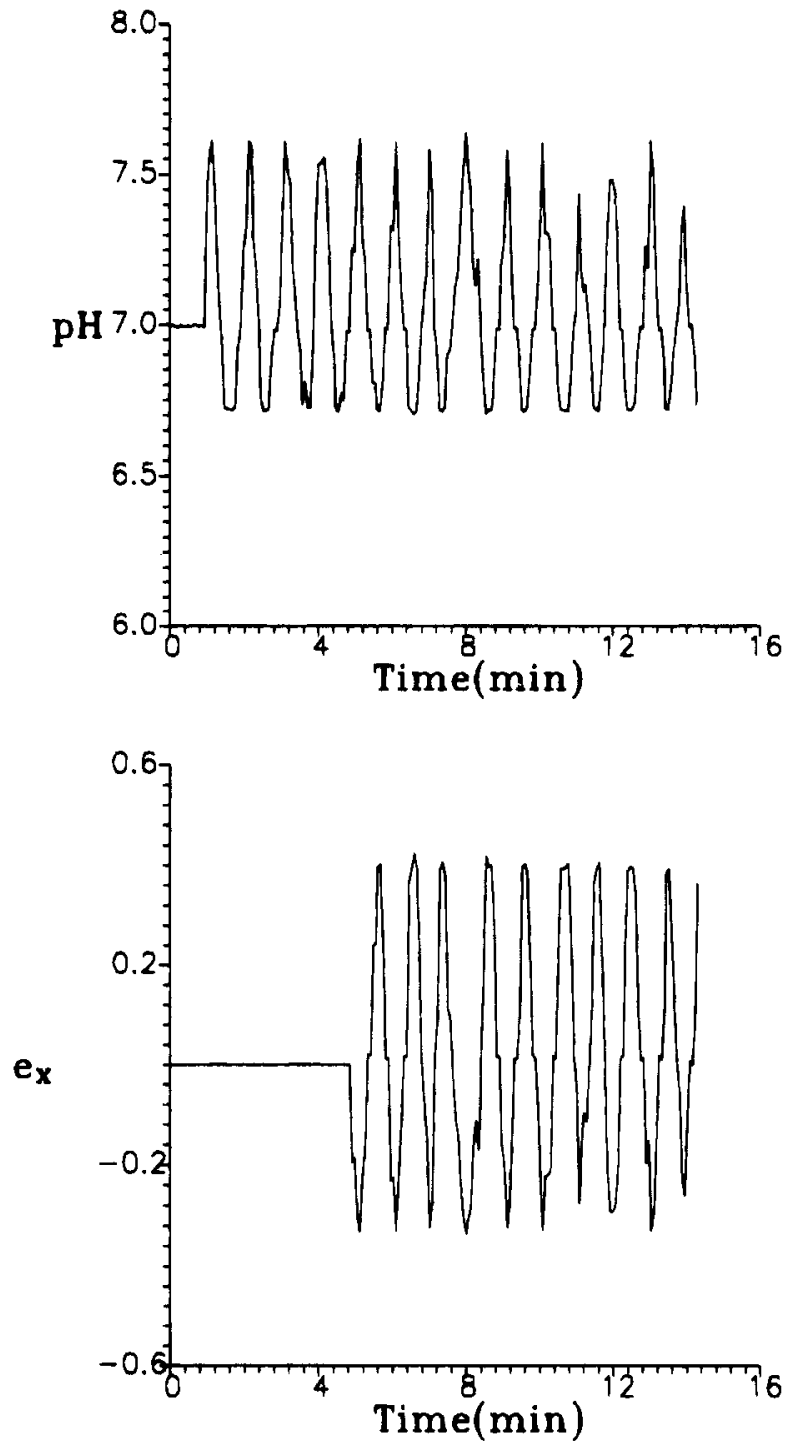

Figure 13. Experimental results from a nonlinear-compensated ATV test.

obtained parameters for the titration curve are $\theta=$ 0.451 and $\xi=0.0112$. Notice that the titration curve parameters employed in the computer simulation are $\theta$ $=0.480$ and $\xi=0.0112$.

Once the titration curve is obtained, the autotune identification continues to find the $K_{u}$ and $\omega_{\mathrm{u}}$ and, subsequently, the nominal tuning constants for the PI controller.

$$
\begin{gathered}
K_{\mathrm{c}}=0.00462 \\
\tau_{\mathrm{I}}=1.85
\end{gathered}
$$

Furthermore, Figure 13 shows that relatively symmetric continuous oscillation can be found for $e_{x}$ as opposed to the asymmetric cycling in $\mathrm{pH}$.

3.3.2. g-ATV. The gain-scheduled PI control is evaluated against the fixed gain (conventional) PI controller. Since the change in the feed flow rate will not change the shape of the titration curve (Figure 1), the load responses for feed flow rate changes are evaluated first. Figures 14 and 15 compare the load responses of the fixed gain PI controller and the gainscheduled PI controller. The results show that superior load responses can be achieved using gain-scheduling. This coincides with our expectation since the nonlinear 
1726 Ind. Eng. Chem. Res., Vol. 34, No. 5, 1995
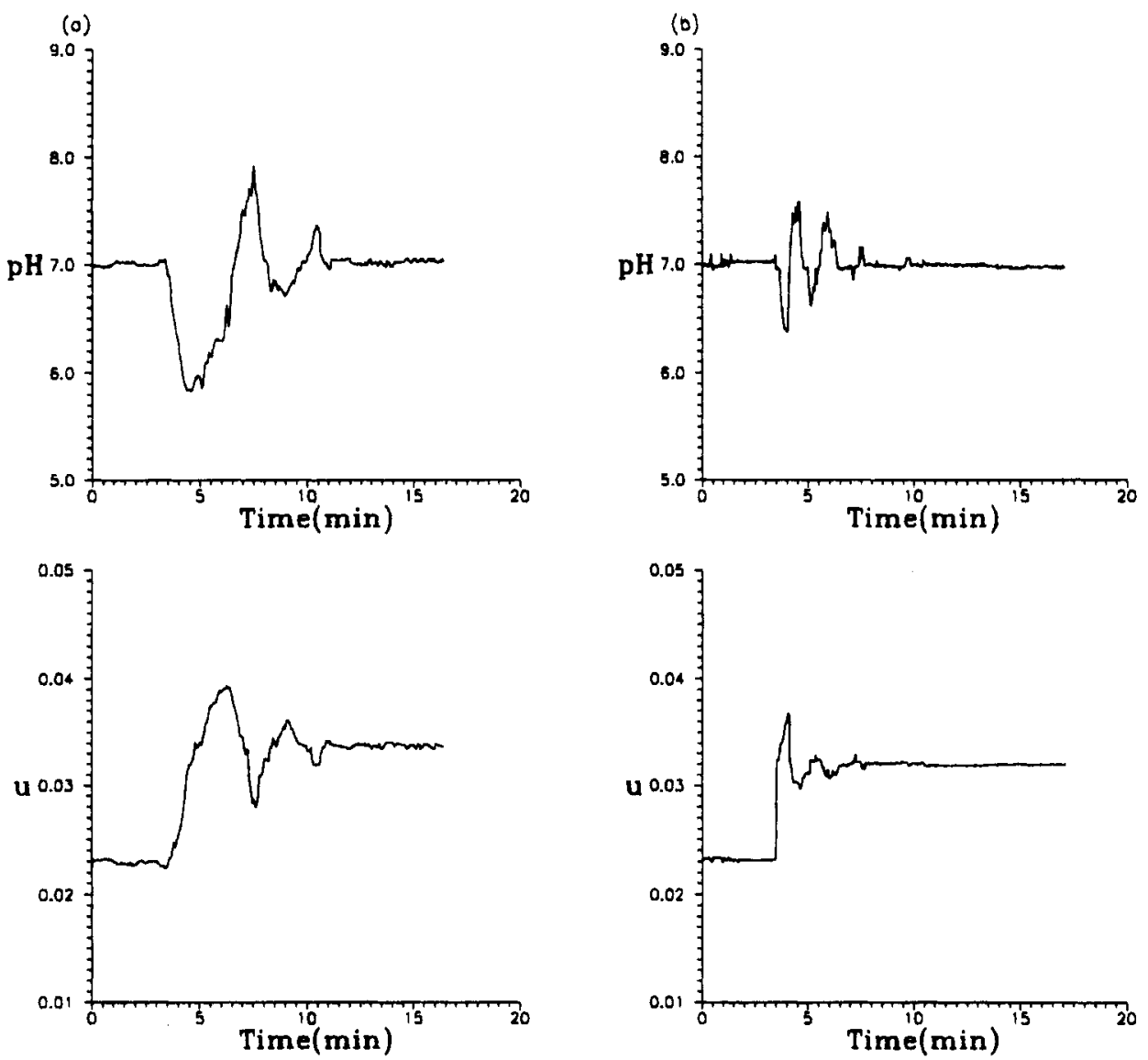

Figure 14. Load responses for a 50\% step increase in feed flow rate with (a) fixed gain PI control and (b) gain-scheduled PI control.
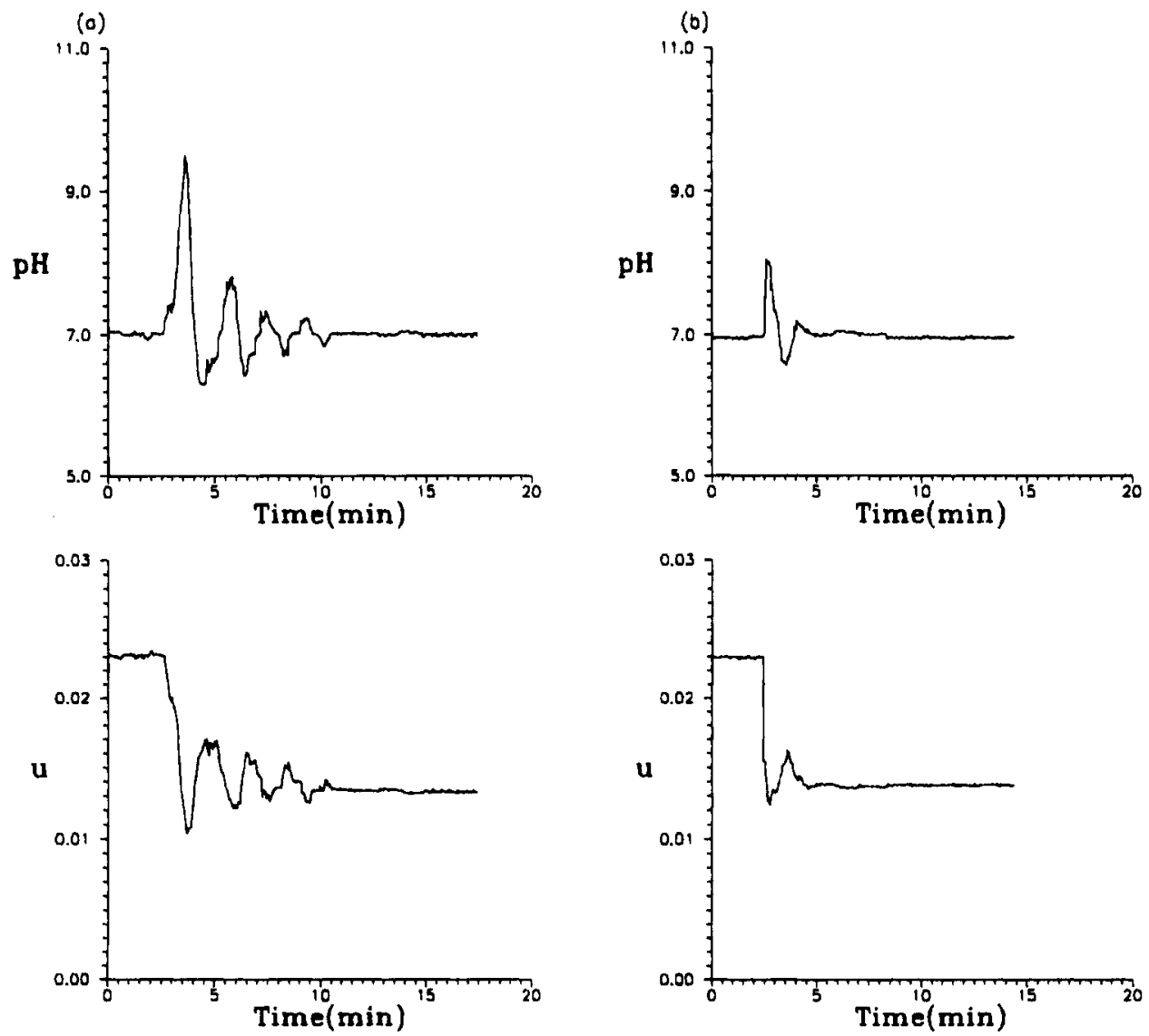

Figure 15. Load responses for a 50\% step decrease in feed flow rate with (a) fixed gain PI control and (b) gain-scheduled PI control. 

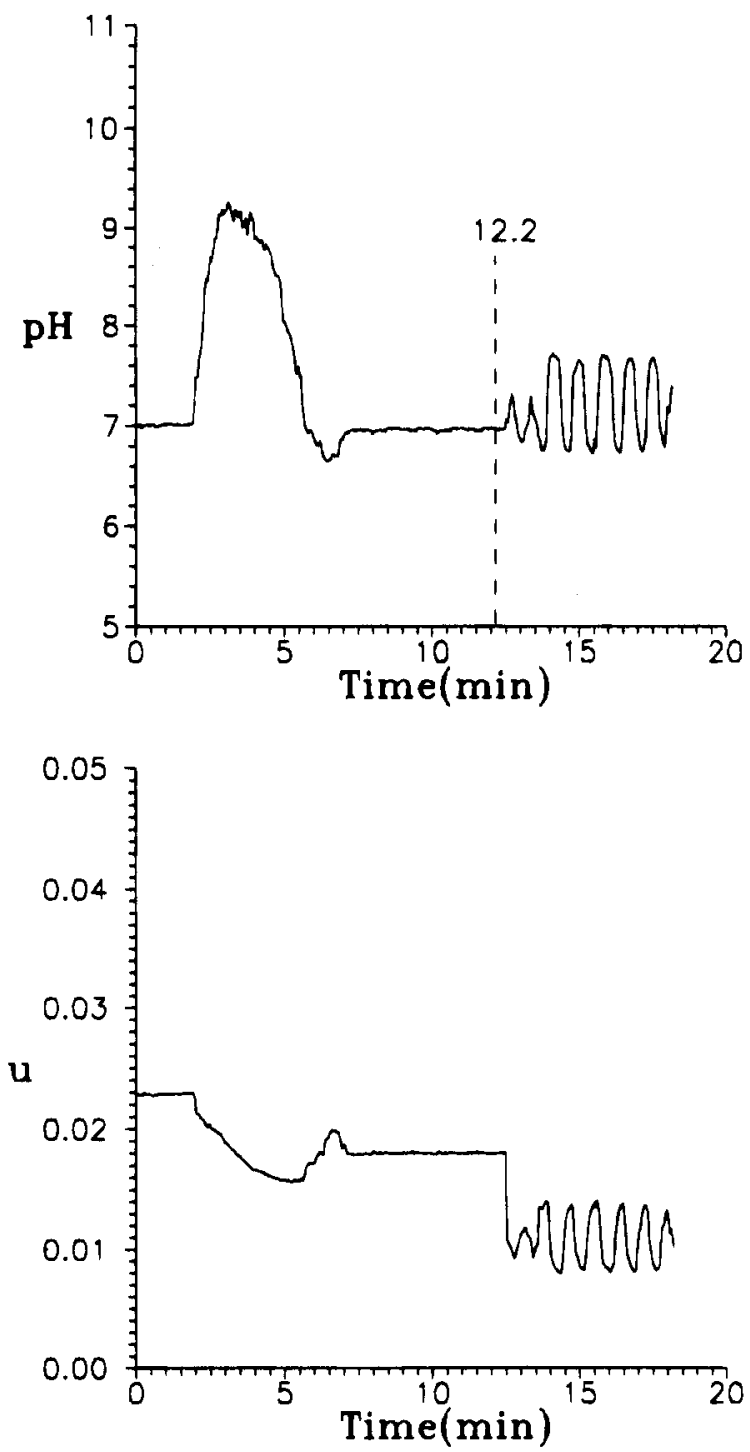

Figure 16. Load responses for a 50\% step decrease in HAc concentration followed by a 50\% step decrease in feed flow rate $(t$ $=12.2 \mathrm{~min}$ ) using gain-scheduled PI control.

compensation can give better responses for highly nonlinear $\mathrm{pH}$ processes.

However, for feed concentration changes, the titration curve changes. Therefore, it is necessary to re-estimate the new titration curve. The whole idea behind the concept of g-ATV is to provide a function (or button) in a single station controller that when it is activated, the g-ATV procedure proceeds to find a new titration curve and the nominal tuning constants. Figure 16 shows that the gain-scheduled PI controller gives an acceptable transient for a 50\% step decrease in the weak acid concentration. If a feed flow disturbance is followed (at $t=12.2 \mathrm{~min}$ ), the gain-scheduled PI control gives a nearly unstable closed-loop response. The reason for that is obvious, since a new titration curve is needed for the nonlinear compensation. The g-ATV can overcome this situation in a straightforward manner. Initially, a 50\% step decrease in the weak acid concentration is introduced (Figure 17). After the transient levels off, the g-ATV procedure is activated (the button is pushed) at $t=10 \mathrm{~min}$. The controller gain is scheduled according to the new titration curve, and the result (Figure 17) shows satisfactory closed-loop performance for a feed flow decrease $(t=25 \mathrm{~min})$. When Figure 17 and Figure 16 are compared, the only difference lies on

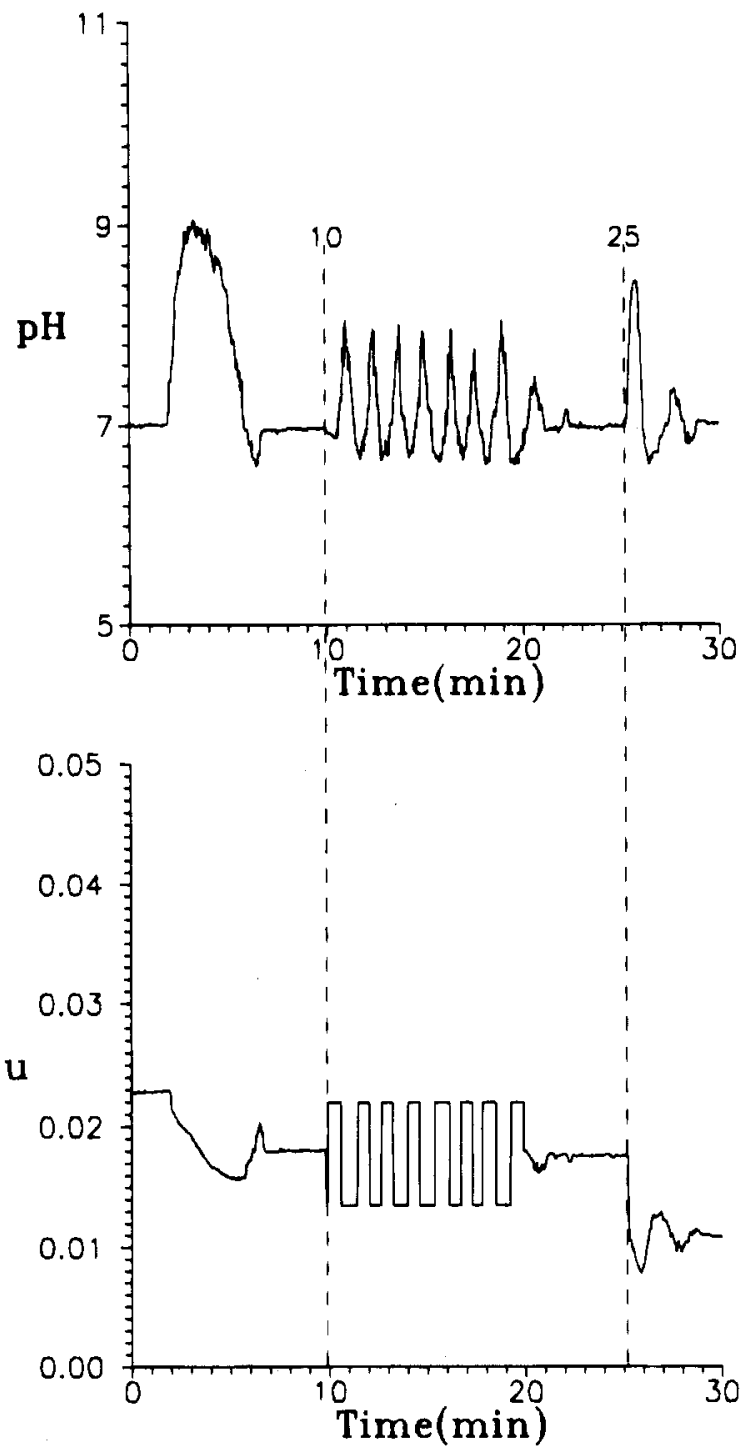

Figure 17. Load responses for a 50\% step decrease in HAc concentration followed by a g-ATV test $(t=10 \mathrm{~min})$ and by a $50 \%$ step decrease in feed flow rate $(t=25 \mathrm{~min})$ using gain-scheduled PI control.

the fact that a new titration curve is employed for nonlinear compensation in Figure 17. Furthermore, identification of the titration curve is carried out effectively following the g-ATV procedure. Notice that the parameters for the new titration curves are $\theta=0.263$ and $\xi=0.0112$. Figure 18 shows both the old and the new titration curves, and the difference between these two curves explains the unstable responses (Figure 16) using the old titration curve.

\section{Conclusion}

The nonlinear $\mathrm{pH}$ control is studied using gainscheduled PI control. The autotune identification is used to estimate the titration curve. Once the titration curve is estimated, the autotune identification continues to find the PI controller parameters. This summarizes the g-ATV procedure. The g-ATV procedure is evaluated experimentally. Results show that, with appropriate instrumentation and model parameterization, robust estimation of the titration curve can be achieved with minimal excitation of the process. More importantly, the results show that reliable nonlinear $\mathrm{pH}$ control can be accomplished in a realistic operating condition. 

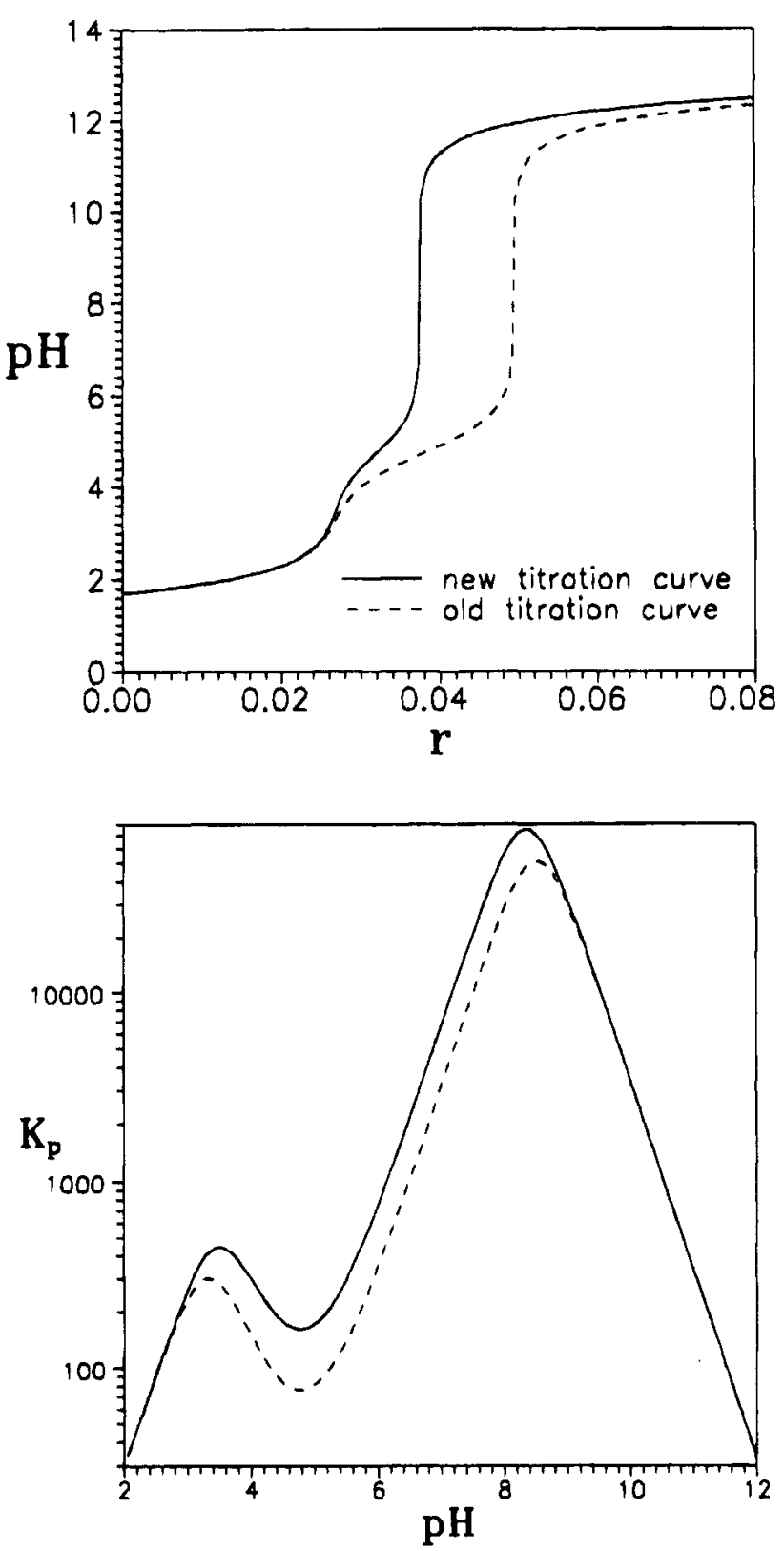

Figure 18. Estimated titration curves and corresponding steady. state gains from the nominal condition and a g-ATV test (Figure 17) for a $50 \%$ step decrease in HAc concentration.

\section{Acknowledgment}

This work was supported in part by the Industrial Development Bureau of Taiwan, ROC.

\section{Nomenclature}

$a=$ amplitude of the limit cycle

$\mathrm{AAD}=$ absolute average deviation

$\mathrm{ATV}=$ autotune variation

CSTR = continuously stirred tank reactor

$F=$ total flow rate out of CSTR, L/min

$F_{\text {acid }}=$ flow rate of process stream flow into CSTR, $\mathrm{L} / \mathrm{min}$

$F_{\text {base }}=$ flow rate of titrating stream flow into CSTR, $\mathrm{L} / \mathrm{min}$

$K_{\mathrm{a}, 2}=$ dissociation constant of HAc

$K_{\mathrm{c}}=$ controller gain

$K_{\mathrm{p}}=$ steady-state gain $(\mathrm{dpH} / \mathrm{d} r)$

$K_{\mathrm{p}}^{*}(\mathrm{pH})=$ slope of line passed through two $\mathrm{pH}$ values

$K_{\mathrm{u}}=$ ultimate gain

$K_{\mathrm{w}}=$ dissociation constant of water

$\mathrm{pH}=-\log _{10}\left[\mathrm{H}^{+}\right]$ $\mathrm{p} K_{\mathrm{a}, 2}=-\log _{10} K_{\mathrm{a}, 2}$

$\mathrm{p} K_{\mathrm{w}}=-\log _{10} K_{\mathrm{w}}$

$P_{\mathrm{u}}=$ ultimate period, $\min$

$r=$ flow ratio $\left(F_{\text {acid }} / F\right)$

$r^{\text {set }}=$ nominal steady-state value of $r$

$T=$ titration curve of process

$T_{i}=i$ th base titration curve

$t=$ time, $\min$

$V=$ volume of CSTR

$x_{1}=$ total ion concentration of $\mathrm{NaOH}\left([\mathrm{NaOH}]+\left[\mathrm{Na}^{-}\right]\right)$in CSTR

$y_{i}=$ total ion concentration of $i$ th acid in CSTR

$\mathrm{Z}-\mathrm{N}=$ Ziegler - Nichols tuning

\section{Greek Symbols}

$\alpha_{i}=$ concentration of $i$ th acid in influent

$\alpha_{i, n}=$ concentration of $i$ th acid in $n$th titration curve

$\beta_{1}=$ concentration of $\mathrm{NaOH}$ in titrating stream

$\omega_{11}=$ ultimate frequency, $\mathrm{min}^{-1}$

$\theta=$ combining factor of $T$ (slope in eq 3 )

$\xi=$ combining factor of $T$ (intersection in eq 3 )

$\tau_{1}=$ reset time for $\mathrm{PI}$ controller, $\mathrm{min}$

\section{Appendix}

The base titration curves selected for the $\mathrm{pH}$ neutralization process are

$$
\begin{aligned}
T_{1}(r, \mathrm{pH})= & \frac{r}{r+1} 0.75-\frac{1}{r+1}[0.00883+ \\
& \left.\frac{0.03}{1+10^{\left(\mathrm{pK} K_{\mathrm{a}, 2}-\mathrm{pH}\right)}}\right]+10^{-\mathrm{pH}}-10^{\mathrm{pH}-\mathrm{p} K_{\mathrm{w}}}=0
\end{aligned}
$$

and

$$
\begin{aligned}
T_{2}(r, \mathrm{pH})= & \frac{r}{r+1} 0.75-\frac{1}{r+1}[0.00883+ \\
& \left.\frac{0.001}{1+10^{\left(\mathrm{p} K_{\mathrm{a}, 2}-\mathrm{pH}\right)}}\right]+10^{-\mathrm{pH}}-10^{\mathrm{pH}-\mathrm{p} K_{\mathrm{w}}}=0
\end{aligned}
$$

where

$$
K_{\mathrm{a}, 2}=1.78 \times 10^{-5}
$$

and

$$
K_{\mathrm{w}}=10^{-14}
$$

\section{Literature Cited}

Åström, K. J.; Hägglund, T. Automatic Tuning of Simple Regulators with Specifications on Phase and Amplitude Margins. Automatica 1984, 20, 645 .

Åström, K. J.; Wittenmark, B. Adaptive Control; Addison-Wesley: Reading, MA, 1989.

Chan, H. C. Experimental Evaluation of Gain Scheduled ATV in pH Control. M.S. Thesis, National Taiwan Institute of Technology, Taipei, 1994.

Gary, D. M. Characterized Feedback and Feedforward Control. ISA Trans. 1981, $20,60$.

Gulaian, M.; Lane, J. Titration Curve Estimation for Adaptive $\mathrm{pH}$ control. Proceedings of the American Control Conference, Sand Diego, CA, 1990; p 1414.

Gustafsson, T. K. An Experimental Study of a Class of Algorithms for Adaptive pH Control. Chem. Eng. Sci. 1985, 40, 827.

Gustafsson, T. K.; Waller, K. V. Dynamic Modeling and Reaction Invariant Control of pH. Chem. Eng. Sci. 1983, 38, 389. 
Lee, J.; Lee, S. D.; Kwon, Y. S.; Park, S. Relay Feedback Method for Tuning of Nonlinear $\mathrm{pH}$ Control System. AIChE J. 1993, 39, 1093.

Lin, J. Y.; Yu, C. C. Automatic Tuning and Gain Scheduling for pH Control. Chem. Eng. Sci. 1993, 48, 3159.

Luyben, W. L. Derivation of Transfer Functions for Highly Nonlinear Distillation column. Ind. Eng. Chem. Res. 1987, 26, 2490.

Luyben, W. L.; Eskinat, E. Nonlinear Auto-Tune Identification. Int. J. Control 1994, 59, 595.

Mahuli, S. K.; Rhinehart, R. R.; Riggs, J. B. Experimental Demonstration of Non-linear Model Based In-Line Control of pH. J. Process Control 1992, 2, 145.

Piovoso, M. J.; William, J. M. Self-Tuning pH Control: A Difficult Problem, An Effective Solution. InTech 1985, 32(5), 45.

Shen, S. H.; Yu, C. C. Use of Relay Feedback Test for Automatic Tuning of Multivariable Control System. AIChE J. 1994, 40, 627.

Shinskey, F. G. $p H$ and pION Control in Process and Waste Streams; John Wiley \& Sons, Inc.: New York, 1973.
Williams, G. L.; Rhinehart, R. R.; Riggs, J. B. In-Line ProcessModel-Based Control of Wastewater pH Using Dual Base Injection. Ind. Eng. Chem. Res. 1990, 29, 1254.

Wright, R. A.; Kravaris, C. Nonlinear Control of $\mathrm{pH}$ Processes Using the Strong Acid Equivalent. Ind. Eng. Chem. Res. 1991, $30,1561$.

Wright, R. A.; Soroush, M.; Kravaris, C. Strong Acid Equivalent Control of pH Processes: An Experimental Study. Ind. Eng. Chem. Res. 1991, 30, 2437.

Received for review August 30, 1994 Revised manuscript received January 30, 1995 Accepted February 9, $1995^{\circledR}$

IE940518+

${ }^{\otimes}$ Abstract published in Advance ACS Abstracts, April 1, 1995. 